\title{
ТАТЬЯНА ФЕДОСЕЕВА
}

iD https://orcid.org/0000-0002-5540-5051

Рязанский государственный университет

им. С. А. Есенина

Факультет русской филологии и национальной культуры

Кафедра литературы

390000 Рязань

ул. Свободы, д. 46

t.fedoseeva@365.rsu.edu.ru

\section{Я. П. ПОЛОНСКИЙ КАК ПРЕДШЕСТВЕННИК РУССКОГО СИМВОЛИЗМА: ПОЭТИКА ЛИРИЧЕСКОГО ЦИКЛА (СНЫ ПОЛОНСКОГО И ЖИЗНЬ МОЕГО ПРИЯТЕЛЯ БЛОКА ${ }^{1}$}

\section{YAKOV POLONSKY AS A PREDECESSOR OF THE RUSSIAN SYMBOLISM: THE POETICS OF THE LYRICAL CYCLE (POLONSKY'S DREAMS AND THE LIFE OF MY FRIEND BY BLOK)}

Творческое наследие Я. П. Полонского мировоззренчески и чертами поэтики предшествовало русскому модернизму в целом и символизму в частности. В. С. Соловьев обосновывал эту общность романтической направленностью личности поэта и ее устремленностью к идеалу. Полонский предварил русский символизм тем, что, утверждал идеальное начало в формах действительной жизни. Органичность его творчества программе младших символистов состояла в абсолютном доверии художественному образу как «символу религиозной реальности» (А. А. Асоян). В лирических циклах Полонского и Блока показана драматическая разобщенность сообщества людей, утративших духовные смыслы бытия. Следствием этой утраты становится страдание и смерть (мотив Возмездия). Наиболее напряженным моментом в развитии лирического сюжета у Полонского является одиночество героя в абсолютной темноте и пустоте безжизненного мистериального пространства. У Блока одиночество героя показано в антитезе неподвижного «отменного порядка» обыденности стихийному движению порожденных сном воспоминаний, предчувствий, мыслей. Сны Полонского завершаются мотивом Преображения через обретение тайной книги. Цикл Блока - утверждением посмертного страдания богоотступника. Сюжетно-мотивный анализ двух циклов позволяет установить их родственность на уровне символического функционирования мотивного комплекса апокалиптического сюжета.

Ключевые слова: лирический цикл, Я. П. Полонский, «младосимволисты», А. А. Блок, человек и общество, апокалиптический сюжет.

${ }^{1}$ Публикация подготовлена при финансовой поддержке РФФИ, проект № 17-04-00501ОГН-А „Литературное наследие Я. П. Полонского: исследование и комментарий” на 2019 год. 
The creative heritage of Yakov Polonsky foreruns the Russian modernism on the whole and symbolism in particular in terms of both the worldview and the features of poetics. Vladimir Solovyov explained this connection by pointing to the romantic vein in the personality of the poet and to his striving for the ideal. Polonsky was the forerunner of the Russian symbolism in that he affirmed the ideal in the forms of real life. The convergence between his work and the programme of the young symbolists consisted in the absolute reliance on the image as a "symbol of the religious reality" (Aram Asoyan). The lyrical cycles by Polonsky and Blok that are discussed show a dramatic disunity of a community of people who have lost spiritual values of life. The result of this loss is suffering and death (the motive of Retribution). The moment of the highest tension in the development of the lyric plot in Polonsky's work is the loneliness of the protagonist in the absolute darkness and emptiness of a lifeless space of a mystery. Blok shows the loneliness of his protagonist in the antithesis between the motionless "perfect order" of an ordinary life and the spontaneous movement of reminiscences, of anticipation and of thoughts, all born from dreams. Polonsky's Dreams close with the Transfiguration achieved through obtaining a mysterious book. Blok's cycle, in turn, ends with a sentence of suffering in the afterlife for the apostate. The analysis of the plot and motives in the two cycles makes it possible to ascertain their affinity on the level of the symbolic functioning of the motif complex of the apocalyptic plot.

Keywords: lyrical cycle, Yakov Polonsky, young symbolists, Aleksandr Blok, man and the society, an apocalyptic plot.

Родственность лирического творчества Я. П. Полонского русскому символизму была осмыслена самими символистами «новой волны». Не проходят мимо этого значимого факта и современные литературоведы, обращая особе внимание на отдельную тему «Полонский и Блок». В развернутом исследовании Н. Ю. Грякаловой к рассмотрению этой темы привлечены, в ряду других, материалы из архива А. А. Блока и в результате углубленного анализа сделан вывод о том, что «Полонский через посредство Соловьева помогал Блоку постигать человеческое. И именно человеческое в единстве разных его проявлений определило художественные устремления Блока в начале 1910-х гг.»². Л. Ф. Алексеева, изучая творчество Блока по отношению к лирическому наследию его старшего современника, обнаруживает «совпадение некоторых поэтических идей, символов и мотивов» ${ }^{3}$. А. А. Асоян отмечает органичность эстетической природы таланта Полонского программе младших символистов в обусловленности поэтического образа религиозным сознанием: «Для Блока, как, впрочем, и для Полонского, “женственная Тень”, Царь-девица и другие подобные мифы были не мечтой, а символами религиозной реальности» ${ }^{4}$. Погруженность

${ }^{2}$ Н. Ю. Грякалова, К генезису образности ранней лирики Блока (Я. Полонский и Вл. Соловьев), [в:] Александр Блок. Исследования и материалы, вып. 2, Ленинград: Наука 1991, с. 51.

3 Л. Ф. Алексеева, Наследие Я. П. Полонского в творческом восприятии А. А. Блока, [в:] Я. П. Полонский: творчество, судьба, эпоха: сб. науч. ст., сост. и науч. ред. Т. В. Федосеева, Рязань: Рязанский государственный университет им. С. А. Есенина 2015, с. 106.

${ }^{4}$ А. А. Асоян, Лирика Я. П. Полонского в ретроспективе Серебряного века, [в:] Я. П. Полонский: творчество, судьба, эпоха..., с. 125. 
сознания поэта в особую «реальность» обнаруживается в символических образах и мотивах, сочетающих в своей структуре идеальные представления с реалий действительной жизни. Этот аспект творческих схождений Полонского и Блока представляет особый интерес в связи с осуществляемым нами исследованием, в котором сопоставляется два лирических цикла: Сны (1856-1860) Полонского и Жизнь моего приятеля (1914) Блока.

В этом выборе мы руководствуемся, прежде всего, особой значимостью в поэтике Полонского циклообразования, уже неоднократно становившегося предметом научного исследования. Так, О. В. Мирошникова в течение ряда лет разрабатывает тему контекстных форм в русской лирике последней трети XIX века. Тенденцию к «соединению разнородных фрагментов в единое мотивное и архитектоническое целое» исследовательница объясняет испытываемой поэтами потребностью в «метафорическом выражении мировидения» на определённом этапе личностного развития 5 . Полонского исследовательница называет «новатором, нашедшим собственные пути создания и трансформации циклических жанров» ${ }^{6}$. Развитие тенденции к циклизации и созданию больших контекстных форм в лирике замечено также многими исследователями творчества русских символистов, и, прежде всего, Блока. Обусловлена эта тенденция сложной ситуацией смены культурных парадигм и духовно-нравственных ориентиров в России конца XIX - начала XX века, которая требовала от поэтов углубленного анализа и все более развернутого представления о духовном составе собственной личности. Так, О. В. Никандрова пишет о «всплеске» цикличности в поэзии Серебряного века, объясняя его стремлением к реализации возобладавшей на данный момент в сознании поэтов «мироустроительной идеи» ${ }^{7}$

Исходя из вышесказанного, свою исследовательскую задачу мы видим в рассмотрении символической природы двух лирических циклов Я. П. Полонского и А. А. Блока в контексте их творческого диалога, что послужит уточнению характера их мировоззренческих и поэтологических сближений.

О близости художественного сознания Я. П. Полонского творческой программе «младших» символистов можно судить по статье В. С. Соловьева Поэзия Я. П. Полонского (1896). В оценке поэзии старшего современника вдохновитель новой волны русского символизма исходил, по справедливому

${ }^{5}$ О. В. Мирошникова, Символика звука и света как основа архитектонической иельности тирической книги Я. П. Полонского «Вечерний звон», «Филологический класс» 2005, № 13, с. 45.

${ }^{6}$ Там же.

${ }^{7}$ О. В. Никандрова, Изменение жанровой семантики лирического циикла в поэзии начала $X X$ века, «Вестник Православного Свято-Тихоновского гуманитарного университета», серия III: Филология, 2013, вып. 1 (31), с. 64. 
замечанию современного исследователя, из собственной философско-эстетической концепции «мистериального, софийного понимания чувства красоты как места сопредельности двух миров», а смысл творчества сводил к познанию «духовной, трансфизической сущности красоты» ${ }^{8}$. Поставив Полонского в ряд с «истинными поэтами», Соловьев дал развернутую характеристику его поэтического таланта и особо отметил стремление примирить в человеке и мире земное (обыденное) с небесным (идеальным). Стихотворение Царь-девица (1880) было интерпретировано в контексте соловьевского духовно-этического учения о Красоте, а заглавный образ определен как «источник поэзии», «сверхчеловеческий, “запредельный” и вместе с тем совершенно действительный и даже как бы личный»- «существо и истинная сущность всех существ, и если она является как тень, то не от земных предметов» ${ }^{9}$.

Действительно, в лирическом сюжете стихотворения Полонского образ Царь-девицы является герою из некоего запредельного пространства: «И жила та Царь-девица, / Недоступна никому». Наделенный родственными фольклорному персонажу способностями, образ растворяется в природе: «шелестит в тени берез», «роняет ключи» и «капли слез». «Яркий, влажный глаз» Царь-девицы оберегает позднее возвращение героя, который не столько видит, сколько интуитивно чувствует ее присутствие, находясь своим сознанием в состоянии между сном и явью, творческой фантазией и действительной жизнью. Чудесная дева присутствует в его жизни лишь намёком, не открываясь полностью, хотя и сопровождает всю его жизнь.

В детстве Царь-девица является в облике сказочной красавицы:

На челе сияло солнце,

Месяц прятался в косе,

По косицам рдели звезды, -

Бог сиял в её красе... ${ }^{10}$.

В юности - олицетворяет собой желание любви: «Всколыхнулась занавеска, / Вспыхнул роз махровых куст, / И, закрыв глаза, я встретил / Поцелуй

${ }^{8}$ М. В. Яковлев, В поисках эсхатологического мифа: Достоевский и русские символисты второй волны, «Вестник Московского городского педагогического университета». Серия «Филологическое образование» 2012, № 2, с. 47-48.

${ }^{9}$ В. С. Соловьев, Поэзия Я. П. Полонского, [в:] он же, Философия искусства и титературная критика, вступ. статья Р. Гальцевой и И. Роднянской, Москва: Искусство 1991, c. 519-520.

${ }^{10}$ Я. П. Полонский, Полное собрание стихотворений, Санкт-Петербург: Издание А. Ф. Маркса 1896, т. 2, с. 201. Далее это издание цитируется с указанием автора, тома и страницы в круглых скобках (Пол., 2, с. 201). 
душистых уст». В зрелости предстает идеалом Красоты, к которому всецело устремлен поэт. По словам Соловьева, «много поэтических мыслей, благородных чувств и чудесных образов внушила не изменившему ей певцу его Царь-девица» ${ }^{11}$.

Образ Царь-девицы растворен в биографических реалиях поэта и свидетельствует об атмосфере уютного и зеленого старинного города Рязани, где вырос Полонский. В его семье сохранялся патриархальный уклад, свойственное русскому дворянскому быту совмещение книжной культуры с устнопоэтической, простонародной, о чем мы можем судить по воспоминаниям поэта ${ }^{12}$. Из того же источника нам известно о присущей будущему поэту от рождения впечатлительности, развитой склонности к самоуглубленному анализу как особенности его творческого сознания, что было связано также и с культивируемым в семье направлением духовной жизни. Полонский вспоминал о владевшем им «религиозном настроении»: то об отроческом желании стать иноком, то о произносимых в полусне молитвах, о говении в доме бабушки и о церковной службе $\mathrm{e}^{13}$.

Образ Царь-девицы проникнут чертами, указывающими на несомненную связь творческого воображения поэта с фольклорной и литературной традициями. Такое совмещение было обусловлено упомянутым в тех же воспоминаниях Полонского бытованием в домашнем быту устных - фольклорных - и поэтических - печатных - текстов, до которых большой любительницей была мать поэта. На рецептивный характер образа фольклорному тексту обратила внимание в своей статье Н. Ю. Грякалова ${ }^{14}$. Нельзя не заметить также, что изобразительно он сближен с одним из видений Иоанна Богослова в тексте Откровения (Апокалипсиса): «И явилось на небе великое знамение: жена, облеченная в солнце; под ногами ее луна, и на главе ее венец из двенадцати звезд. Она имела во чреве, и кричала от болей и мук рождения» (Откр. 12: 1-2). В сюжете Откровения мотив рождения готовит духовное Преображение мира - явление «нового неба и новой земли», а привлечение текста Апокалипсиса к интерпретации образа Царь-девицы позволяет связать его с идеей духовного возрождения человечества.

Известно, что Полонский глубоко переживал духовную неустроенность современного ему русского общества. В 1876 году он писал

${ }^{11}$ В. С. Соловьев, Поэзия Я. П. Полонского..., с. 521.

${ }^{12}$ Я. П. Полонский, Старина и мое детство, [в:] он же, Проза, сост., вступ. ст., примеч. Э. А. Полоцкой, Москва: Сов. Россия 1988, с. 268-326.

${ }^{13}$ Я. П. Полонский, Старина и мое детство..., с. 303-305.

${ }^{14}$ Н. Ю. Грякалова, К генезису образности ранней лирики Блока (Я. Полонский и Вл. Соловьев)..., с. 54-56. 
из Санкт-Петербурга Ф. М. Достоевскому, с которым долгие годы поддерживал теплые отношения, о распространении вокруг «духа розни и нравственного распадения» ${ }^{15}$. Разочарованность в массе погруженных в мелочные жизненные интересы обывателей, составляющих большую часть образованного общества, наиболее последовательно и прямо выражено поэтом в стихотворении Проходите толпою, трусливо блуждающей... $(1886)^{16}$. В своей жизни «толпа» сосредоточена на ложных ценностях и самолюбивых устремлениях, ее «тешит сытая ложь», занимает «роскошь праздных затей». «Тощий ум» приземленного сознания, в понимании поэта, бесплоден, он не способен оставить следующему поколению «ни решенных задач, ни побед». В финале стихотворения, несмотря на резкое неприятие распространенных в современной ему русской жизни умонастроений, поэт выражает надежду на то, что в будущем русский человек «пожелает простора для мысли и гения» и тогда воссияет «заря обновления» (Пол., 2, с. 339-340).

Родственные настроения, судя по всему, владели в начале 1910-х годов А. А. Блоком. К этому времени относятся первые наброски и планы его неоконченной поэмы «Возмездие». В одном из набросков так сформулирована лирическая идея произведения: «В этой поэме я хочу указать на пропасть между общественным и личным, пропасть, которая становится все глубже» ${ }^{17}$. В неоконченной поэме Блок собирался раскрыть внутреннюю жизнь русского человека предреволюционных лет. В эти годы, по его словам, людьми овладело «трагическое сознание неслиянности и нераздельности всего - противоречий непримиримых и требовавших примирения» (Блок, 2, с. 271). Блок, как и Полонский, видит причину кризисного состояния общества в ложном характере возобладавших в умах современников идей. В тексте поэмы утверждается, что «железный» XIX век бросил «беспечного человека» в «ночь умозрительных понятий» (Блок, 2, с. 276). (Очевидно, имелись в виду идеи богостроительства.) Ложные пути духовных исканий определяются поэтом как «гуманистический туман»:

Там, в сером и гнилом тумане,

Увяла плоть и дух погас,

${ }^{15}$ Я. П. Полонский, Письмо Ф. М. Достоевскому, [в:] Из архива Достоевского. Письма русских писателей, ред. и вст. ст. Н. К. Пиксанова, Москва; Петроград 1923, с. 75.

${ }^{16}$ Датируется нами по: Полонский Я. П., Письмо Д. В. Аверкиеву от 2 марта 1886 года, [в:], Архив Д. В. Аверкиева, РО РНБ, ф. 6, ед. хр. 3435, лл. 5-6.

${ }^{17}$ А. А. Блок, План первой части, [в:] он же, Собрание сочинений: в 6-ти тт., под общ. ред. М. А. Дудина, В. Н. Орлова, А. А. Суркова, Ленинград: «Художественная литература» 1980 , т. 2, с. 368. Далее тексты Блока цитируются по этому изданию с указанием автора, тома и страницы в круглых скобках (Блок, 2, с. 348). 
И ангел там священной брани,

Казалось, отлетел от нас...

(Блок, 2, с. 277).

Очевидно, что общность и глубина переживания двумя поэтами развивавшегося на их глазах духовного кризиса не могла не отразиться в общности выраженных в поэзии каждого из них идей, сходстве поэтических приемов, родственности мотивов, сюжетов, образов.

Цикл Я. П. Полонского Сны создавался на протяжении нескольких лет, отдельные его части публиковались в журналах «Современник» и «Русское слово» в 1856-1859 годах. В составе пяти стихотворений цикл вошел в Собрание сочинений Я. П. Полонского в 4 томах ${ }^{18}$. Волей автора был закреплен его состав и названия четвертой и пятой частей: Подсолнечное изарство и Тишь и мрак.

В первых двух стихотворениях задан общий тон всем последующим. Они построены на антитезе «жизнь-сон». Сны лирического героя полны света и радости: ему видится «румяное солнце», в пространстве сна «божий белый день» рождает ощущение молодости, радостные «сердца движенья». Возвращение в действительный мир связано с холодом и глубоко переживаемым одиночеством лирического героя. Одиночество тяготит, при том, что вокруг множество людей: «...толпа за толпою / Снует мимо окон моих». Избавление от одиночества приходит лишь во сне, между тем как в жизни образуется пустота мнимых отношений. Бессмысленной суете окружения поддается и сам герой стихотворения:

\footnotetext{
И ходят послушные ноги,

И движутся руки мои;

Без мысли язык мой лепечет,

И сердце болит без любви.

(Пол., 1, с. 316).
}

Смысл антитезы «жизнь-сон» нарушает привычную логику: сон оказывается более «живым», ценностно и эмоционально насыщенным, и противостоит духовной пустоте - «обезжизненной» действительности.

Антитеза «жизнь-сон» трансформируется в третьем стихотворении цикла Полонского в мотив тюрьмы. Тюрьма символизирует одиночество и несвободу героя в мире людей. В обстановке ночи, в разлившемся вокруг

${ }^{18}$ Я. П. Полонский, Собрание сочинений: в 4-х тт., Санкт-Петербург; Москва: Изд-во М. О. Вольфа 1869, т. 2, с. 60-69. 
безжизненном лунном свете подчеркнуты символические детали - «чёрная решетка» и тёмный, погасший «ночник». Пространство тюрьмы служит объективации кризисного душевного состояния лирического героя, а через него - и самого автора. Мотив тюрьмы, восходящий к христианскому мотиву «тело - тюрьма души», тесно связанный с одиночеством поэта в «толпе» и мотивом «земное существование как тюрьма, заключение», стал одним из наиболее распространенных в лирике русских поэтов 1880-1890-х годов неоромантиков К. К. Случевского, К. М. Фофанова, а также ранних символистов Д. Н. Минского, В. Я. Брюсова, К. Д. Бальмонта и других, о чем убедительно говорят наблюдения и выводы А. Ханзен-Лёве ${ }^{19}$.

Более глубокое разочарование в обществе, сравнительно с героем Снов, переживает лирический герой цикла А. А. Блока Жизнь моего приятеля, датированный 1915 годом. В первой части цикла развивается тема суетной «бессмысленности дел», в их нагромождении теряется единственная возможность для отдохновения - сон, который бежит, лишая радости сновидения:

И рад бы ты уснуть, но - страшная минута!

Средь всяких прочих дум -

Бессмысленность всех дел, безрадостность уюта

Придут тебе на ум.

(Блок, 2, с. 219).

Блок прямо указывает на «безверие» как причину бессмысленности бытия: «На дне твоей души, безрадостной и черной, / Безверие и грусть» [выделено мною: Т. Ф.]. В тягостном душевном состоянии блоковского героя видится «проклятие» и торжество злой силы: «Как будто ночь на всё проклятие простерла, / Сам дьявол сел на грудь!» (Блок, 2, с. 216-217).

Во второй и третьей частях цикла Блок развивает мотивы несвободы, болезни и смерти души. Его герой не сумел сохранить свою душу в чистоте, его жизнь «тяжко дремлет взаперти». Болезненный свет луны распространяется повсюду: «Так приплюснут диск больной, / Заплевавший все в природе / Нестерпимой желтизной». «Диск больной» луны лишает жизни все живое и вводит героя в болезненное состояние, которое разрешается мотивами потерянного сердца и смерти души. В развитии этих мотивов можно видеть аллюзии не только на Сны Полонского, где родственным образом функционирует мотив луны и смерти души, но и на другие его стихотворения: Рассказать ли тебе, как однажды... (1864), Плохой мертвеи (1865). Их объединяет

${ }^{19}$ А. Ханзен-Лёве, Русский символизм. Система поэтических мотивов. Ранний символизм, Санкт-Птеребург 1999, с. 91-107. 
сюжет о похоронах сердца, разбитого безответной любовью и равнодушием окружающих. Стих Блока Сердие - крашеный мертвеи как символ умершей души может быть прямо отнесен к воспоминаниям Полонского о детской влюбленности. Один из его рассказов содержит описание эпизода с вырезанным из картона сердцем, предназначенным для юной красавицы, в которую был влюблен ребенком будущий поэт. Этот эпизод завершается насмешкой взрослых, жестоко ранившей влюбленного ${ }^{20}$.

В шестой части блоковского цикла развивается заявленный в Снах Полонского мотив «жизнь-сон». Герой Блока осознает суетную пустоту обыденной жизни, «малых трудов» и «мелочных забот». В стихотворении воссозданы узнаваемые реалии времяпрепровождения образованной русской элиты начала XX века, не столько бытовых (болезни, врачи, лекарства, записка: «Поставьте розы на стол»), сколько духовных и творческих (Христос, поклонники Пушкина, Надсон, футуризм, символизм, реализм и др.). Дни героя проходят «как всегда / В сумасшествии тихом»- в череде пустых слов и ничего не значащих отношений.

Установившийся порочный порядок нарушается сном, который внутренне меняет героя. Просыпаясь, тот чувствует живое движение души и духа: он взволнован «...воспоминанием смутным / Предчувствием тайным», в его сознании «буйно» бьются «слишком светлые мысли». В том, как жизненная содержательность сна противоположна бессодержательной действительности очевидна аллюзия на Сны Полонского. Очевидна и родственность связанных с пошлостью обыденной суеты мотивов безумия, воспоминания, счастья молодого неведения. Только, в отличие от героя Полонского, пробуждающегося к новой жизни, у Блока антитеза «жизнь-сон» разрешается малодушным желанием героя вернуться к «тихому сумасшествию» мелочной повседневности.

Цикл Полонского Сны завершается стихотворением Тишь и мрак, где в безжизненной пустоте пребывает небо: в нем горят, «как смола», «неподвижные звезды», и «месяц холодный, как будто мертвец» стоит среди «могильных холмов». Космическое небытие распространяется на землю, где «природа как будто не дышит», а все живое оказывается «в объятиях мертвого сна». Мертвенность неба и земли усугубляется полным одиночеством героя, оказавшегося в обстановке абсолютно безжизненного мрака, тишины и покоя:

И стал я блуждать в этом мраке

Один - как слепец. Не ночной -

Могильный был мрак, и повсюду

${ }^{20}$ Я. П. Полонский, Проза..., с. 306. 
Была тишина и покой.

(Пол., 1, с. 142).

Одиночество героя безысходно, ничем и никем не может быть восполнено: «...тьму обнимал я, и тьма обнимала меня».

Такая же безвыходность отличает положение блоковского героя. В пятой части цикла Пристал ко мне нищий дурак... представлен диалог, в конце оказавшийся внутренним, произошедшим в сознании самого героя, однако этот диалог проясняет сокровенное желание найти понимание и сочувствие в другом. Обращаясь к мнимому собеседнику герой сообщает, чего он ждет от другого человека:

Чтоб стал ты, как я, откровенен,

Как я, в униженьи, смиренен,

А больше, мой друг, ничего.

(Блок, 2, с. 219).

В реальном общении разговор о главном для героя невозможен, оно сводится к обыденным мелочам - и в этом причина его «тихого сумасшествия».

Из неподвижности замершей природы и духовного опустошения героя стихотворения Полонского Тищь и мрак развивается мрачный образ апокалиптического, иного бытия:

\footnotetext{
И вдруг с лёгким треском всё небо

Подвинулось - звёзды текут -

И катится месяц, как будто

На нём гроб тяжёлый везут.

И тёмные тучи печальным

Над ним балдахином висят.

И красные звёзды, как свечи,

Повитые крепом, горят...

(Пол., 1, с. 323).
}

В мире произведения ложные цели и разобщенность людей в земном пространстве накладывает отпечаток на космическое и вселенское. Трагическое одиночество человека окрашивает мрачными красками жизнь целиком, выведенную из фантастического пространства и символической «тюрьмы» сна в мистериальное пространство.

Разрешение трагедии апокалипсиса герой Полонского получает благодаря некой таинственной книге. Именно она возвращает героя к жизни. 
Эпизод с книгой может быть интерпретирован в контексте Откровения Иоанна Богослова, где доступ к «книге за семью печатями» позволяет увидеть то, «чему надлежит быть после сего» (Откр.4:1). Провиденциальные видения Иоанна являют страшную череду картин, рисующих страдания людей и гибель мира, и связываются с прорицанием «нового неба и новой земли, ибо прежнее небо и прежняя земля миновали» (Откр. 21: 1).

И. Г. Вьюшкова справедливо увидела в Снах Полонского «цикловой сюжет», который «оставляет гнетущее впечатление неоднозначности мира и человеческого сознания, ищущего выход из одиночества» ${ }^{21}$. Однако нельзя не заметить, что таинственная книга в тексте стихотворения служит пробуждению героя и символизирует его обновление, как раз и обозначая выход из жизненного тупика:

\author{
О Боже мой! где я!! - сквозь щели \\ Затворенных ставень сквозят \\ Лучи золотые, то солнца \\ Глаза золотые глядят. \\ Глядят и смеются - и сердце \\ Очнулось - и, жизни привет \\ Почуя, взыграло, как будто \\ Впервые увидело свет... \\ (Пол. 1, с. 327).
}

Символическое значение финала лирического цикла Полонского, несомненно, жизнеутверждающее. Сквозь щели ставень в комнату героя пробиваются животворные лучи солнца. Это вовсе не «мертвое» солнце апокалипсиса: его «золотые глаза» «глядят и смеются», совсем в духе игривой Царь-девицы, являвшейся герою стихотворения в полусне или полуяви, лишь намеком, движением, жестом. Очевидно, что завершая апокалиптический сюжет мрачных сновидений героя, Полонский расставляет наиболее значимые для себя содержательные акценты: утверждает ценности жизни не в физической, а в духовной сфере, способной к душеспасительному росту. Развращенность и духовное самоуничижение человечества воспринято им, соответственно логике Откровения Иоанна Богослова, как не окончательное - оно предшествует рождению «новой земли и нового неба».

Таким образом, в тексте лирического цикла Полонского Сны может быть отмечено зарождение свойственного Серебряному веку циклического

${ }^{21}$ И. Г. Вьюшкова, Мотивный комплекс сна в поэзии и прозе Я. П. Полонского, «Сибирский филологический журнал» 2011, № 3, с. 91. 
и контекстного единства произведений с привлечением к его оформлению последовательности апокалиптических мотивов. М. В. Яковлев в своем исследовании русской поэзии начала XX века определяет такое единство «как систему поэтических откровений» из которых выстраивалось контекстовое единство цикла, лирической книги, сборника - «художественное пространство, философски и эстетически направляемое символами, развертывающимися в апокалиптическую сюжетность» 22.

Рассматривая цикл Блока Жизнь моего приятеля с точки зрения такого единства, заметим, что от его героя, в отличие от героя Полонского, мистериальное пространство скрыто. В текстах цикла оно не получает изобразительной ясности, присутствуя подспудно в реалиях действительной жизни, и содержательно проясняется лишь в заключительных седьмой и восьмой частях цикла: Говорят черти, Говорит смерть.

Черти призывают героя к греховной жизни, пагубным для души страстям. Их речь завершается словами о возможном прозрении, когда человек «в исступленном покаяньи» воспротивится их воле и неминуемо погибнет физически, и о том, что лишь они смогут поддержать его в этот момент:

\footnotetext{
И станешь падать, - но толпою

Мы все, как ангелы, чисты,

Тебя подхватим, чтоб пятою

О камень не преткнулся ты...

(Блок, 2, 221).
}

В таком развитии сюжета можно видеть аллюзию на текст лермонтовского Демона, в финале которого возникает спор Демона с Ангелом за душу Тамары. У Лермонтова в этом споре побеждает Ангел, у Блока - черти готовы завладеть телом героя, выдавая себя за ангелов.

Окончание седьмой части цикла $О$ камень не преткнулся ты может быть рассмотрен в качестве перифраза фрагмента из евангельского текста. В Евангелии от Матфея этот стих цитируется дьяволом с отсылкой на текста девяностого псалма. Фрагмент относится к искушению Иисуса словом Священного Писания:

[...] Потом берет Его диавол в святой город и поставляет Его на крыле храма, и говорит Ему: если Ты Сын Божий, бросься вниз, ибо написано: Ангелам Своим заповедает

${ }^{22}$ М. В. Яковлев, Апокалиптическое направление в русской поэзии XX века: спеициика авторского мышления, религиозные идеи и символы, жанрово-стилевые решения: автореф... доктора филол. наук, Москва 2017, с. 10. 
о Тебе, и на руках понесут Тебя, да не преткнешься о камень ногою Твоею [...] (Мф. 4: 5-6) [выделено мною: Т. Ф.]

Мотив «черта-ангела» может быть сопоставлен также и с текстом Откровения Иоанна Богослова об Антихристе как олицетворении лжи и клеветы, несущем людям зло под личиной добра. Следовательно, мотив «черти-ангелы» блоковского цикла, являясь аллюзией на новозаветные тексты, включается в апокалиптический сюжет и служит развитию авторской мысли о пребывающем в страдании греховном человечестве и ожидающем его Возмездии.

В восьмой части цикла голос смерти обращен к обезумевшему от душевных страданий и впавшему в грех богоотступничества герою Блока:

Когда осилила тревога,

И он в тоске обезумел,

Он разучился славить Бога

И песни грешные запел

(Блок 2, с. 221).

Дойдя в своем страдании до края, герой ищет путь к «блаженной двери» смерти, но не получает успокоения и у нее.

Очевидно, что в лирическом герое блоковского цикла угадываются черты рефлектирующего героя Полонского: оба одинаково тяготятся бессмысленностью суетного существования современного общества, погрязшего в тщеславных побуждениях и ложных стремлениях, оба трактуют его как следствие богоотступничества, оба ощущают недостаточность внутренних сил, чтобы противостоять ему и ищут выхода в области духа.

Мысль Блока о человеке близка мысли Полонского, он тоже обусловливает состояние духовного тупика сомнением и неверием. В то же время нельзя не заметить более оптимистичный взгляд Полонского, мировоззренчески прочно связанного с пушкинской идеей «самостоянья» человека и принадлежавшего времени не крайней степени развития, а лишь начала духовного кризиса русского общества. Несмотря на разрушительное действие «железного века», он сохранял надежду на духовное возрождение. Блок был более пессимистичен, особенно в начале 1910-х годов, когда остро переживал кризис жизнестроительной идеи символизма. Во время работы над циклом Жизнь моего приятеля им было написано еще одно чрезвычайно значимое для нашего исследования стихотворение «Ну, что же? Устало заломлены слабые руки...» (1914). В нем человеческая слабость осмыслена через мотив предательство Иуды (евангельская цитата в последнем стихе: «Что делаешь, 
делай скорее») и апокалиптические мотивы закатившегося солнца, тайной книги и лежащей на человеке вины духовного отступничества:

Ведь солнце положенный круг обойдя, закатилось.

Открой мои книги: там сказано все, что свершится.

Да, был я пророком. Пока еще сердце молилось...

(Блок, 2, с. 223).

Лишь через несколько лет, пережив глубокое разочарование и обретя новую почву под ногами, он напишет:

[...] рано или поздно все будет по-новому, потому что жизнь прекрасна. Жить стоит только так, чтобы предъявлять безмерные требования к жизни: все или ничего; ждать нежданного; верить не в “то, чего нет на свете”, а в то, что должно быть на свете; пусть сейчас этого нет и долго не будет. Но жизнь отдаст нам это, ибо она - прекрасна [...] (Блок, 4, с. 235).

Кризисное состояние общества передается Полонским и Блоком через состояние духовного надрыва человека. В поэтике произведений он получает выражение в комплексе символических мотивов: «жизнь-сон», «жизнь-тюрьма», «жизнь-могила», «смерть души», «закат солнца», «гибель мира», «тайная книга». Сходные символические мотивы служат созданию лирического сюжета по апокалиптическому типу, в последовательности снов-откровений и картин сверхъестественной реальности, включенных в реалии действительной жизни. По-своему прочитанный каждым из поэтов текст Откровения Иоанна Богослова послужил воплощению мировосприятия, отмеченного духом времени, у Полонского - с выражением надежды на рождение «нового неба и новой земли», у Блока - чувства гибельной безнадежности, восторжествовавшего на момент написания цикла.

\section{References}

Alekseeva, Lubov F. Nasledie Ya. P. Polonskogo v tvorcheskom vospriyatii A. A. Bloka. In: Ya. P. Polonskii: Tvorchestvo, sudba, epokha, ed. T. V. Fedoseyeva. Razan, 2015: 118-127.

Asoyan, Aram A. Lirika Ya. P. Polonskogo v retrospektive Serebryanogo veka. In: Ya. P. Polonskii: Tvorchestvo, sudba, epokha, ed. T. V. Fedoseyeva. Razan, 2015: 118-127.

Blok, Aleksandr A. Sobranie sochinenii: v 6-ti tt., ed. M. A. Dudin, V. N. Orlov, A. A. Surkov. Leningrad: Khudozhestvennaya literatura, 1980-1983.

Gryakalova, Natalya Yu. K genezisu obraznosti rannej liriki Bloka (Ya. Polonskii i Vl. Solovyev). In: Aleksandr Blok. Issledovania i materialy, vypusk 2, ed. Yu. K. Gerasimov. Leningrad: Nauka, 1991: 49-63. 
Iz arxiva Dostoevskogo. Pisma russkikh pisatelei, ed. N. K. Piksanov. Moskva; Petrograd, 1923.

Miroshnikova, Olga V. "Simvolika zvuka i sveta kak osnova arkhitektonicheskoi tselnosti liricheskoi knigi Ya. P. Polonskogo Vechernii zvon". Filologicheskij klass, no. 13 (2005): 45-50.

Nikandrova, Olga V. "Izmenenie zhanrovoi semantiki liricheskogo tsikla v poezyi nachala XX veka". Vestnik Pravoslavnogo Svyato-Tikhonovskogo gumanitarnogo universiteta. Seria III: Filologia, vypusk 1 (2013): 63-70.

Polonskii, Yakov P. Pismo D. V. Averkievu. In: Arkhiv D. V. Averkieva, Rukopisnyi otdel Rossijskoi natsionalnoi biblioteki, f. 6, ed. khr. 3435, ll. 5-6.

Polonskii, Yakov P. Polnoe sobranie stikhotvorenii: v 5-ti tt. Sankt-Peterburg: Izdanie A. F. Marksa, 1896.

Polonskii, Yakov P. Proza, ed. Ye. A. Polochkaya. Moskva: Sovetskaya Rossiya, 1988.

Polonskii, Yakov P. Sobranie sochinenii: v 4-kh tt, vol. 2. Sankt-Peterburg; Moskva: Izd-vo M. O. Volfa, 1869: 60-69.

Solovyev, Vladimir S. Filosofia iskusstva i literaturnaya kritika, vstup. stat'ya R. Galchevoi i I. Rodnyanskoi. Moskva: Iskusstvo, 1991.

Vyushkova, Irina G. "Motivnyi kompleks sna v poezyi i proze Ya. P. Polonskogo". Sibirskii filologicheskii zhurnal, no. 3 (2011): 90-94.

Yakovlev, Mikhail V. Apokalipticheskoe napravlenie v russkoi poezyi XX veka: spetsifika avtorskogo myshlenia, religioznye idei i simvoly, zhanrovo-stilevye resheniaa: avtoref. ... doktora filol. nauk. Moskva, 2017.

Yakovlev, Mikhail V. "V poiskakh eskhatologicheskogo mifa: Dostoevskii i russkie simvolisty vtoroj volny". Vestnik Moskovskogo gorodskogo pedagogicheskogo universiteta. Seriya "Filologicheskoe obrazovanie", no. 2 (2012): 47-48. 